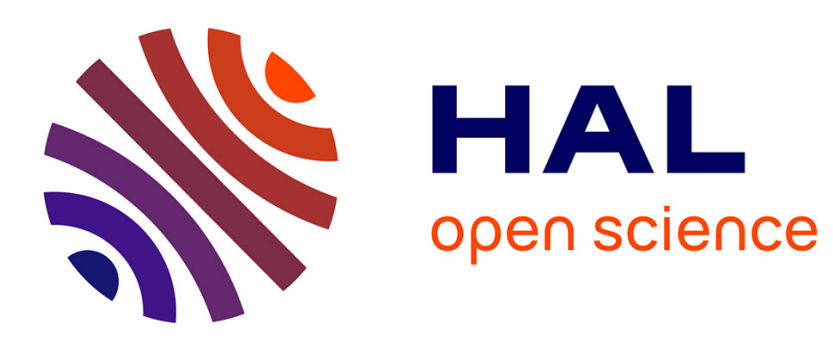

\title{
Engineering affective atmospheres on the moving geographies of the 1897 Andrée expedition
}

Derek P. Mccormack

\section{To cite this version:}

Derek P. Mccormack. Engineering affective atmospheres on the moving geographies of the 1897 Andrée expedition. cultural geographies, 2008, 15 (4), pp.413-430. 10.1177/1474474008094314 . hal00572049

\section{HAL Id: hal-00572049 \\ https://hal.science/hal-00572049}

Submitted on 1 Mar 2011

HAL is a multi-disciplinary open access archive for the deposit and dissemination of scientific research documents, whether they are published or not. The documents may come from teaching and research institutions in France or abroad, or from public or private research centers.
L'archive ouverte pluridisciplinaire HAL, est destinée au dépôt et à la diffusion de documents scientifiques de niveau recherche, publiés ou non, émanant des établissements d'enseignement et de recherche français ou étrangers, des laboratoires publics ou privés. 


\title{
Engineering affective atmospheres on the moving geographies of the 1897 Andrée expedition
}

\author{
Derek P. McCormack \\ School of Geography, Oxford University Centre for the Environment
}

\begin{abstract}
How might the dynamic materiality of atmosphere be addressed in ways that register simultaneously its meteorological and affective qualities? The present article considers this question via a discussion of the kinds of atmospheric spaces in which the emergence and experience of modern balloon (or aerostatic) flight is implicated. In doing so it argues that aerostatic flight can be understood simultaneously as a technology for moving through atmosphere in a meteorological sense and as an event generative, at least potentially, of atmospheres in an affective sense. This argument is exemplified via a discussion of a particularly notable instance of balloon flight: the attempt, in 1897 by a Swedish engineer, Salomon August Andrée, and two companions, to fly to the North Pole in a hydrogen-filled balloon. Drawing upon a range of contemporaneous accounts, the article makes three claims about the expedition: first, that it can be understood, following Spinoza, as an effort to engineer a mode of addressing the meteorological atmosphere as a relational field of affect, second, that the passage of the expedition can be understood in terms of the registering of atmospheres (in both meteorological and affective terms) in moving, sensing bodies; and third, that the expedition was also generative of a distributed space of anticipation and expectancy. In concluding, the article speculates upon how conceiving of atmospheric space as simultaneously as meteorological and affective might contribute to recent attempts to rethink the materialities of cultural geographies.
\end{abstract}

Keywords: affect $\cdot$ Andrée $\cdot$ atmosphere $\bullet$ emotion $\bullet$ feeling $\bullet$ materiality $\bullet$ Spinoza

\section{Introduction}

7 his article explores how atmosphere might be addressed and understood as a space that is simultaneously processual, distributed, and sensed. In doing so, it provides an account of the materiality of atmospheric space that aims to move between two ways in which that term is registered and understood. The first is atmosphere in a meteorological sense: atmosphere as a turbulent zone of gaseous matter surrounding the earth and through the lower reaches of which human and non-human life moves. The second is atmosphere in an affective sense: something distributed yet palpable, a quality of environmental immersion that registers in and through sensing bodies while also remaining diffuse, in the air, ethereal. ${ }^{1}$

In seeking to hold together both senses of atmosphere the article is intended as a contribution to emerging efforts within and beyond the sub-discipline of cultural geography to interlace two important trajectories of thinking. The first trajectory revolves around attempts 
to think through the materiality of landscapes and environments in ways that avoid rehearsing a division between two distinct ontological domains: one cultural and the other physical. ${ }^{2}$ As various scholars have argued, both landscape and environment might better be apprehended in processual terms: as shifting fields of materiality within which certain sensibilities and visibilities circulate and precipitate. ${ }^{3}$ The second, and related, trajectory revolves around questions of affectivity within geography, and the degree to which these questions provide ways of thinking through the processual materiality of environments. Of particular importance here is a growing realization of the necessity of attending to and through the differentiated nature of affectivity, and more specifically, to the difference between categories of affect, as a field of pre-personal intensity; feeling as that intensity registered in sensing bodies; and emotion as the socio-cultural expression of that felt intensity. ${ }^{4}$ The distinctions between these categories are increasingly well articulated, and the aim of this article is not so much to rehearse their origin, emergence or ongoing development. Rather, it argues for the importance of foregrounding such a differentiated conception of affectivity in any attempt to rethink the materiality of atmosphere in terms that are simultaneously meteorological and affective. In doing so it aims to demonstrate how such differentiation allows the affectivity of atmosphere to be understood in ways that engage a range of more-than-human processes and relations while also remaining attentive to how these processes and relations are potentially sensed in moving bodies as so many intensities of feeling.

This argument is developed via a particular methodological strategy: following the movement of an aerostatic body - or lighter-than-air balloon - through the different kinds of atmospheric space in which this movement is implicated. Pursuing the movement of a specific 'thing' in this way is not so much evidence of the necessity of anchoring the narrative of the article onto a reassuringly material object: instead, the aim is to follow the ongoing transformation of an aerostatic body through the distributed and differentiated affective materiality of atmospheric space. ${ }^{5}$ More specifically, the article focuses on a particularly notable instance of aerostatic flight: the attempt in 1897, by a Swedish engineer, Salomon August Andrée, and two companions, to fly to the North Pole in a hydrogen-filled balloon. By drawing upon a range of contemporaneous accounts, including the diaries and notes left by the expedition members, the article narrates the atmospheric spaces of the expedition in three ways. First, through a discussion of how the Andrée expedition can be understood, following Spinoza, as an effort to engineer a solution to the problem of polar travel by addressing the meteorological atmosphere as a field of relations of affect. Then, and second, through a consideration of how the passage of the expedition can be understood in terms of the registering of atmospheres (in both meteorological and affective terms) in moving, sensing bodies. Third, and finally, the article outlines how the movement of the expedition was productive of distributed space of anticipation and expectancy, in which it continued to circulate and be sensed long after its disappearance.

The article is organized as follows. To begin, it provides an overview of the relation between aerostatic bodies and different ways of thinking and experiencing atmospheric space. Following a brief introduction to the Andrée expedition, the article then discusses how the movement of this expedition unfolds as a differential passage between atmospheres that are simultaneously meteorological and affective. In concluding, the article speculates upon how 
thinking of atmospheric spacing in this way might contribute to ongoing efforts to rework the materialities of cultural geographies.

\section{On atmospheres and aerostatic bodies}

In a number of recent articles the anthropologist Tim Ingold has discussed how meteorological phenomena have been treated within the social sciences and humanities. ${ }^{6}$ For Ingold such phenomena have often been framed in terms of an ontological division between the material and the immaterial, where the former refers to the earthbound and concrete, and the latter to something tethered loosely above or around the grounded concreteness of terra firma. As he puts it, "following what is by now a familiar line of thought, the surface of the earth has become an interface between the concrete and the imaginary. What lies below (the earth) belongs to the physical world, whereas what arches above (the sky) is sublimated to thought'. Underpinned by this division, most work about these phenomena has tended therefore to address the symbolic and cultural significance of atmosphere and weather in human society. ${ }^{8}$ And in doing so, such accounts have also underplayed the animate agency of phenomena such as wind, frost, ice, and fog. For Ingold, in contrast, atmospheric phenomena including weather need to be thought instead as part of a field of moving materiality that registers differentially in the perceptual affordances of sensing bodies.

Following Ingold then, there are various ways through which to trace the registering and sensing of the materiality of atmospheric space. One way would be to revisit and rethink particular kinds of artistic representation as an attempt to depict the distributed and diffuse space of atmosphere. Another might be to focus on the phenomenological experience of certain atmospheric and meteorological phenomena by attending to how such phenomena figure as lively participants in various kinds of animism. As Ingold puts it, in animist 'ontology, ... the properties of the medium through which [living beings move] are all-important. That is why the inhabited world is constituted in the first place by the aerial flux of weather rather than by the grounded fixities of landscape'. While suggestive, such cultures of animism are not the only source from which we might begin rethinking the relations between the materiality of earth-atmosphere relations. It might also be possible to do so by following the movement of a range of more or less than human bodies: bodies whose affective materiality is not necessarily reducible to the terms of an individual subjective experience. And it might also be possible to rethink the moving materiality of these relations through contexts that are often juxtaposed to any effort to think through affectivity: contexts involving the engineering of technological devices. ${ }^{10}$

Aerostatic bodies - or lighter-than-air balloons - provide a useful vehicle through which to undertake such rethinking, and precisely because their emergence facilitates distinctive ways of experiencing and relating to atmospheric space. ${ }^{11}$ The significance of the balloon as an aerostatic body in this regard can be understood in three ways. First, the balloon offered a technical and scientific instrument through which to gather data about atmospheric processes. In this sense, the balloon is central to the emergence of atmosphere as the object of scientific practice: put another way, it participates in the process by which atmosphere is rendered 'explicit' 
as a distinct zone of moving matter. ${ }^{12}$ Then, and second, the balloon offered a vehicle through which to explore the imaginative dimensions of earth-atmosphere relations. Perhaps most notable in this regard is Jules Verne's Five weeks in a balloon in which a group of British explorers fly from east to west across the continent of Africa. ${ }^{13}$ Then, and third, the balloon facilitated a new kind of immersive experience of atmosphere. Aerostatic flight seemed to provide a privileged opportunity for the educated mind to experience atmospheric space directly. As one observer put it: 'undisturbed by the interference of ordinary impressions, [the balloonist's] mind more readily admits the influence of those sublime ideas of extension and space which, in virtue of his exalted station, he is supremely and solely calculated to enjoy.'. ${ }^{14}$

The experience of balloon flight was more than contemplative however - it was also profoundly affective. In one of the few sustained critical commentaries on the cultural significance of ballooning, Elaine Freedgood has suggested that the wide appeal in Victorian Britain of this practice had much to do with the kind of emotional experiences of which aerostatic flight was generative. ${ }^{15}$ This experience, argues Freedgood, was amplified by the aesthetic contours of the wider 'geography of risk' in which it was situated: in this context the sense of being co-extensive - if not overwhelmed by - the immensity of the atmosphere offered one vehicle for the cultivation of aesthetic individuality in a world which appeared increasingly disenchanted by rationality, industrialization and secularization. The prevalence of descriptions of this experience in accounts of Victorian balloon flight leads Freedgood to explain its significance via psychoanalytic theories of regression. For Freedgood, balloon flight afforded the possibility of regressing, however temporarily, to the 'oceanic feelings' of the infant, a state in which the subject has yet to differentially precipitate as a discrete, self-contained individual. In these terms, the balloon, as aerostatic thing, becomes an experiential-aesthetic vehicle for the immersion of the self in the object-less, and vaguely womb-like world of the atmosphere. Such a psychoanalytic reading of the affective nature of balloon flight has some merit. Yet it also has a number of significant limitations. Of most consequence is the fact that by placing primacy on the psychical and the cultural as the key registers through which the affective experience of balloon flight are explained, the participation of the distinctive affective materiality of both atmosphere and aerostatic bodies in such experience is underplayed. Furthermore, it becomes all too easy to cast the experience of atmospheric immersion as a kind of infantile regression, rather than something through which it might be possible to rethink the nature of the atmospheres in which bodies move.

The remainder of this article considers a specific episode of aerostatic flight - the Andrée expedition - as a vehicle through which to rethink the affective materiality of atmosphere in ways that are not reducible to such psychoanalytic terms. Departing from Danes Island (Danskøya) on 11 July 1897 from the northwest corner of the Svalbard archipelago Salomon August Andrée and his two compatriots, Nils Strindberg and Knut Fraenkel aimed both to reach the North Pole and to 'explore as much as possible of the North Polar Region in Geographical respects'. ${ }^{16}$ Refracted through the lens of critical scholarship about practices of exploration, the Andrée expedition appears as a peculiarly idiosyncratic exemplification of the wider imperatives of late 19 th century polar voyaging. ${ }^{17}$ Appealing directly to Swedish nationalism, ${ }^{18}$ it provided a vehicle through which the imperial ambitions of that country could be potentially realized. Furthermore, insofar as one of the key aims of the expedition was to investigate the use of the balloon as a platform from which to map photographically the 
Arctic, Andrée's endeavour can be read in terms of the enactment of a cartographic imperative to render legible unmapped surfaces of the earth.

While the rationale and justification for such exploration can be explained via a range of scientific, geopolitical and imaginative factors, the practices and conduct of exploration also involve technical engagements with the problem of how to inhabit and become mobile in polar regions. ${ }^{19}$ As Urban Wråkberg has argued, by the end of the 19th Century, polar exploration was going through something of a 'logistical crisis', with 'all the techniques of travel [having] been tested without any major breakthrough'. ${ }^{20}$ Andrée's balloon provided one possible solution to this crisis. Arctic travel by balloon, Andrée argued, had obvious advantages over the various competing methods then employed in the service of polar exploration. It would obviate the dangers and difficulties of man-hauling [sic] across the ice, and would remove the necessity of spending months if not years in 'vessels which are carried like erratic blocks, frozen fast to wandering masses of ice'. ${ }^{21}$ The balloon therefore offered the prospect of a relatively quick and far less strenuous route to the North Pole, one that avoided any requirement to contend with the shifting materiality of ice and water.

Andrée's declared confidence in the possibilities afforded by his balloon might well be understood as an attempt to transcend the trials and tribulations of a more corporeal mode of dwelling in the Arctic, and as a desire to transcend the limits of the body as a necessary vehicle of and for successful polar exploration. It might also be read as the exemplification of a certain kind of masculinist faith in the possibilities of engineering as a vehicle of technical progress: faith rooted deeply in a form of rationalism that disavowed emotion. Indeed, the figure of Andrée seems the very embodiment of the technocratic engineer. Contemporaneous accounts present him as a sober technological rationalist: someone for whom the body is a mere instrument in the pursuit of technical and scientific knowledge. This is the Andrée who, during his participation in the first International Polar Year (1881-84) submitted himself to a peculiar experiment to determine the effect of the long Arctic night on skin colour. Remaining indoors for one month, he emerged with apparent proof that lack of exposure to sunlight causes the skin to acquire a greenish hue. At the same time, Andrée appears as someone in possession of a remarkable determination to remain as unaffected as possible by emotion and feeling. This is the Andrée, who, in his own words, 'abhorred the idea of marriage because it involved "factors which cannot be arranged according to plan". And this is the Andrée who, when he felt a 'few heart leaves sprouting' said 'I resolutely pull them up by the roots. ... I know that if I once let such a feeling live, it would become so strong that I dare not give in to it'. ${ }^{22}$

So it would be easy, perhaps, to rehearse a critical narrative of the Andrée expedition in terms of how it exemplifies the extent to which the disavowal of emotional embodiment becomes a necessary element of manly and heroic polar exploration. And it would be tempting to frame the expedition in terms of an unspoken, perhaps repressed desire on the part of Andrée to experience the kinds of oceanic feelings about which Freedgood writes. Yet, as this article seeks to demonstrate, such critical narratives are complicated if affectivity is differentiated, and in ways that allow us to think of atmosphere as a space whose moving materiality is transversal to any attempt to divide the meteorological from the affective. Thus, in what follows, the Andrée expedition emerges in different ways, as an attempt to address atmosphere as a field of affect and as an event generative of a distributed atmosphere of 
expectancy. And the passage between both atmospheric spaces is registered through moving bodies of variable speeds and slowness.

\section{Addressing affective bodies}

How then might we begin thinking about the aerostatic bodies and affective atmospheres of which the passage of the Andrée expedition consists? In the middle of things: in the middle of the relations of which the expedition, as an event, is composed. And in the middle of this event is a peculiar kind of moving still point: an enveloped body of hydrogen gas, an aerostatic balloon. This balloon is what is most distinctive about the Andrée expedition: it is what potentializes the expedition, what gives it some lift. On the surface, a balloon has a peculiar kind of object-ness, most apparent during the event of ascension and flight. But as an aerostatic body - a balloon (and particularly Andrée's balloon) - and its relation to the atmosphere through which it moves, needs to be understood in more dynamic terms. Spinoza's thinking provides a useful source of orientation here, particularly insofar as it offers a way of conceiving of the affectivity of bodies that does not necessarily reduce this affectivity to the terms of human corporeality.

For Spinoza, bodies are not to be defined in terms of their organic form or functional properties. Nor are they to be defined in terms of the kind of matter of which they are composed. Instead the question of what a body is can be considered equivalent to the ethological question of what a body can do. In a move that reveals the geometrical rationalism underpinning his thinking, Spinoza further defines what bodies can do along two axes. The first of these is kinetic. Because for Spinoza 'all bodies are either moving or at rest', bodies (at least simple bodies) are therefore 'distinguished with respect to motion or rest, quickness or slowness, and not with respect to substance'. ${ }^{23}$ If a group of bodies move at the same speed, or in such a way 'that they communicate their motions one to another in a certain ratio, these bodies are reciprocally called united bodies'. ${ }^{24}$ The second axis is dynamic, and refers to the capacity that a body has to affect, and be affected by, other bodies. Some affective relations and encounters will enhance the capacity of bodies to act, and others will diminish it. While Spinoza concentrates much of his attention on the affects of the human body (corpus bumanum), his analysis extends the category of the body beyond the sphere of the human in ways that creatively rework the division between an aerostatic body and the atmosphere through which it moves. A body, following Deleuze's reading of Spinoza can, for instance, be a gust of wind. It can be defined in terms of kinetic relations: by relations of speed and slowness - the velocity and energy of molecules, differential temperature and pressure gradients. At the same time, it can be defined dynamically, in terms of its capacity to affect other bodies - to alter their speed, direction, and intensity.

If bodies are to be understood in this way, atmosphere is not therefore just a space through which such bodies move. Atmosphere is instead a set of dynamic and kinetic affects, where affect is the pre-individual intensity of relation between bodies. These affects are never just actual, but are 'fringed forever by a more that continuously develops, and that continuously supersedes them'. ${ }^{25}$ Put another way, there is a generative virtuality that pertains to affect, one that is necessary to think the movement of bodies in relation not only to themselves, but to 
a yet to be determined future. In these terms, atmosphere is a field of virtual movement from which certain bodies, including wind, are always in the process of actualizing. As Peter Hallward puts it:

To measure the 'actual' weather at any given moment in time and space is like taking a static snapshot of a process that itself remains in a state of continuous interactive change. The weather is only ever actual in the passing instant of a present moment, but what determines every such actuality is the dynamic motion of atmospheric forces as a whole. This motion or force itself cannot be grasped simply by measuring a series of actual states of affairs to which it gives rise: as motion or energy, it exists in intensive rather than extensive form. ${ }^{26}$

Spinoza's affective cartography therefore provides a way of apprehending the relation between atmosphere and bodies without reinstating the divide Ingold is so concerned to avoid: rather than ontologically separate, bodies and atmospheres are simply two different ways in which intensive substance expresses itself in extension, even if their relative speeds are different. In these terms Andrée's aerostatic balloon body can be situated on Spinoza's cartography of affective relations between bodies of different speeds. Mapping the affects of a hydrogenfilled aerostatic body is rather straightforward: buoyancy, itself dependent upon temperature, and potential catastrophic combustion. Enveloped in some shape or form, a buoyant body of hydrogen can also be affected by a moving body of wind. In fact, under normal conditions, the movement of both bodies will always be in 'agreement'. Andrée himself puts it thus: 'A balloon, which floats perfectly freely in a current of air, moves in exactly the same direction and at precisely the same speed as those of the current of air. This agreement between the current of air and the movement of the balloon makes it useless to provide the balloon with such accessories as sails, rudder, etc'. ${ }^{27}$ As such, a moving body of hydrogen is not dirigible: its direction depends entirely on the wind. Making the balloon dirigible, even in part, requires something else. Internal combustion engines would have provided one solution, had they been sufficiently light and powerful enough. No, what is needed, according to Andrée is the procurement

For the balloon [of] another speed, either greater or less than that of the wind. If it is possible to give the balloon a greater speed than the wind has, it can be steered in all possible directions, even right against the wind. But if the balloon can only be given a speed less than the wind's, it cannot be steered against the wind, but may be made to deviate more or less from the direction of the current of air. ${ }^{28}$

Despite the rhetoric through which his expedition is publicized, as an engineer Andrée is not necessarily concerned with mastery of the air: he is concerned with relations of speed and slowness, with the capacity to slip into the middle of a moving body of air, and, with a little help, modify the relation between that body of air and a buoyant body of hydrogen. How then to engineer the affective capacity of a moving aerostatic body, to modify its relations of speed and slowness? Experiment, even if only unintentionally. ${ }^{29}$ In 1893, in his balloon Svea (Sweden), Andrée launches from Stockholm, and is last seen drifting out over the Baltic. Over nine hours later he manages to land on an island near Turku, in Finland. Despite being unplanned, Andrée's flight generates a minor sensation upon his return to Sweden. It appears also to convince him of the value of guide-ropes in regulating the altitude of a balloon and increasing the distance such a balloon could travel. ${ }^{30}$ The advantage of the drag-lines or guideropes is two-fold. First, they work to regulate the altitude of the balloon. If it becomes too 
heavy, and sinks, the extra weight of the drag-lines is supported by the ground, which means that the balloon will tend to rise again. And if the balloon becomes too buoyant, perhaps as a result of warming by sunlight, the tendency to rise is countered by the extra weight of the ropes. Then, and second, the ropes slow the balloon relative to the speed of the wind. This difference in speed means that if a sail fixed to the balloon is set at an angle against the wind, the balloon should deviate from the direction of the wind.

Andrée's balloon, at least in theory, is an attempt to engineer the capacity to affect and be affected by the wind, but also by the surface of the earth over which the balloon passes, trailing the drag-lines as it does. Less a surface onto which symbolic significance is inscribed, the balloon is better understood therefore as a mode of addressing the atmosphere: a way of entering into a virtual field of kinetic and affective relations. ${ }^{31}$ At best then, Andrée the 'balloonatic' is a kind of cartographer of affect, mapping the kinetic and dynamic relations of a hydrogen-filled, silk-enveloped balloon-body.

\section{Remotely sensed bodies}

The launch of the balloon from Danes Island changes everything. Shortly after ascending, the balloon is forced down towards the water, probably by a wind coming off Danes Island. In these first fraught moments of its flight, The Eagle loses a number of the guide ropes designed by Andrée to give the balloon a degree of dirigibility against the wind. Their loss, combined with the forced jettisoning of a significant quantity of ballast, diminishes severely the capacity of the crew of The Eagle to exercise control over its direction and altitude: in effect, rendering it a free-floating body of hydrogen. Yet despite this incident, no decision to abandon the flight is taken.

The accounts of the flight in the diaries and notebooks kept by members of the Andrée expedition are fragmentary and suggestive. Nor, with some exceptions - such as Strindberg's letters - do these accounts reveal much about the inner emotional lives of the three men. There is little about hope, sadness, fear, joy. The details of which they speak are far more mundane: details of position, of longitude and latitude, of buoyancy, altitude, precipitation, condensation, and drift; of the perceptual confusion of this landscape of ice, fog, and water; of the moving feeling of balloon flight. As the writing of John Wylie has demonstrated, such details reveal how bodies register the effects and affects of polar landscapes through distinctive kinds of sensuous encounters with and within shifting fields of materiality, perception, and affect. ${ }^{32}$ Elsewhere, Kathryn Yusoff has argued that photographic images of polar exploration work as 'archives of the feeling body', simultaneously registering the duration and intensity of light and corporeal exposure in hostile environments. ${ }^{33}$ Similarly, it is possible to understand what remains of the Andrée expedition as such an archive, or perhaps more accurately, as an archive of the remote - yet felt - sensing of atmospheres (as simultaneously meteorological and affective) in moving bodies, where feeling is understood as the registering, or actualizing of a field of affect in a sensing body.

So the diaries, notes, and almanac provide an archive of how the movement of the balloon through an atmospheric field of affect is felt in sensing bodies. And for as long as the balloon journey lasts, what is felt, primarily, is an ongoing modification of buoyancy in 
relation to an atmospheric field. The Eagle's guide-ropes had been designed to regulate this buoyancy, while also, in theory, offering the possibility of a degree of dirigibility. With the loss of these ropes and of a significant amount of ballast at the outset of the journey, the capacity of the three men in the balloon to exercise much control over its altitude and direction is diminished severely. So, from about $1.40 \mathrm{pm}$ on the 11 th of July until sometime after midnight on the 12th, the balloon is in free flight, reaching altitudes of up to 700 metres, far higher than had been intended. From then on, the balloon moves at a much lower altitude, the remaining guide and drag ropes in contact with the surface. With this loss of control, other agencies and processes take over, becoming part of the unpredictable line of continuous variation of which the movement of the expedition consists: its rises and falls, its ascending and descending.

The process of precipitation is crucial here. Surprisingly, Andrée underestimated the frequency of precipitation in the area north of Spitzbergen. And as things turn out, the journey of the balloon becomes an ongoing passage through cloud and fog banks. The most immediate effect of this is to reduce the visibility upon which the photographic element of the expedition depends. Precipitation also becomes disorientation: 'The course and speed cannot be determined for we do not see the ice beneath us. ${ }^{34}$ Moreover, the very nature of the material through and over which they move becomes indeterminate: ' $11 \mathrm{~h} 20 \mathrm{~m}$ Cloud or land? $\mathrm{N} 70^{\circ}$ E. Float at height of $460 \mathrm{~m}$. It was cloud ... 11h $55 \mathrm{~m}$ o'cl. It looks like water and ice along the horizon in $\mathrm{E}$ but it is only the shadow of an altocumulus cloud in E. ${ }^{35}$ But precipitation is more than a clouding of vision. It also affects the buoyancy of the balloon. The fog cools the hydrogen and condenses on the envelope and rigging, often freezing in the form of hoarfrost, adding significantly to the weight of the balloon and reducing further its lifting capacity. And when it thaws, the moisture soaks into the rigging, such that 'everything is dripping and the balloon weighted down'. ${ }^{36}$ This is not, then, the region of 'continuous sunshine' about which Andrée had spoken in 1895, a factor he claimed would maintain 'the temperature of the balloon and air at an extremely equable level', such that there would be 'little alteration in the carrying power of the balloon'. ${ }^{37}$ And when the balloon envelope does pass out of fog or cloud, the hydrogen within is warmed by the sunlight, with a resultant increase in its lifting capacity, and a gain in altitude: '12th July, 4h 50 o'clock. Fog lightens a little and the balloon is rising., 38

In turn, the rising and falling of the balloon modify the permeability of the envelope itself, with the escape of hydrogen registering as 'a soft whistling for a long time in the large valve. ${ }^{3}$ ' Manufactured in Paris, the balloon has been fabricated by sewing together layers of silk, which are then covered with a layer of resin designed to seal the seams: a fabric envelope with about eight million tiny holes. The reliability of this design and the capacity of the balloon to remain aloft for the 30 days Andrée has claimed necessary for the journey had both been questioned before the expedition. Indeed, Nils Ekholm, a member of Andrée's first abortive expedition in 1896, had withdrawn subsequently because of his concerns about the leakage of gas. Despite some testing prior to departure, the capacity of the envelope to retain gas is affected severely by the changes in temperature and altitude experienced by the balloon. Shortly after its fraught ascent, the balloon shoots up to about 700 metres. The resultant drop in the surrounding air pressure allows a significant quantity of hydrogen to escape - about 11,480 cubic feet, translating into a reduction of lifting capacity of about $790 \mathrm{lbs}$ at sea level. ${ }^{40}$ 
If the affects of the balloon become a continuous line of rises and falls, then this line is modified further by the wind - upon which the success of the expedition is dependent. Blowing initially from the southwest during the launch of The Eagle, the wind becomes more westerly in the early hours of the 12th of July. Later that morning it changes direction, blowing from the east for about 15 hours. The loss of some of the guide ropes during the launch means that the crew of The Eagle are in no position to even attempt to alter its course. The balloon becomes a body in almost perfect agreement with another - the wind. Until, at some point, during the night of the 12 July, one of the drag-lines becomes jammed under the ice. At the same time, the wind begins to blow from the north, a wind, which, if the balloon had been free, would probably have carried it back much of the way to Spitzbergen. The balloon 'sways, twists and rises and sinks incessantly. It wishes to be off but cannot'. ${ }^{41}$ The Eagle remains tethered above the ice, its stillness generative of contemplation: 'It is not a little strange to be floating here above the Polar Sea. To be the first that have floated here in a balloon. How soon, I wonder, shall we have successors? Shall we be thought mad or will our example be followed? I cannot deny but that all three of us are dominated by a feeling of pride. ${ }^{42}$

Such contemplative moments are rare however. What remains of the balloon journey becomes an exercise in monitoring and modifying buoyancy. Despite the loss of the guide ropes, the three men can alter this in some ways. Materials, objects, and equipment can be jettisoned. Yet such is the finely balanced relationship between aerostat and atmosphere that they begin to realize that their own sensing bodies have the capacity to modify the affective map of the expedition: ' $6 \mathrm{~h} 35 \mathrm{~m}$ Aée [sic] pisses at the height of $600 \mathrm{~m}$. We rise probably on account of this throwing out of ballast. ${ }^{43}$ And a little later: ' $8 \mathrm{~h} 32 \mathrm{~m}$ We are now travelling horizontally so finely that is a pity we are obliged to breathe, as that makes the balloon lighter of course. And so Fraenkel and I go and spit, too! ${ }^{44}$ Spit and piss become minor modifications of a body's felt capacity to act: ' $9 \mathrm{~h} 41 \mathrm{~m}$ Fraenkel's and Strindberg's available quantities of piss are thrown out. ${ }^{35}$

But this is nowhere near enough. Somewhere around $2.00 \mathrm{pm}$ on $12 \mathrm{July}$, the balloon begins experiencing 'hard and continuous bumps against the ground resulting from the fog that weighs down'. ${ }^{46}$ And this is the way the remainder of the balloon journey proceeds: a series of 'constant bumpings violent', ${ }^{47}$ the nausea inducing monotony of 'touch, new touch, another touch'. 48 The warming effect of sunlight providing a little light relief: 'now and then blue patches, a refreshing sight after all the "stampings" during the night. The carrying power of the balloon also increases finely'. ${ }^{49}$ And moments of escape into the carrying ring: 'one feels so safe there and so at home. One knows that the bumps up there are felt less and this allows one to sit calmly and write without having to hold on. In the carrying-ring the vibrations from the drag-lines are felt somewhat (they are not felt at all in the car) but instead the bumps against the ground are felt much less'. ${ }^{50}$

At $8.11 \mathrm{pm}$ on 14 July the three men jump out of the balloon, and begin preparing for their journey over the pack ice to the northern part of the Svalbard Archipelago, in the knowledge that they are equipped for a 'balloon expedition, for [a] journey to be carried out by balloon, [as] travellers [reliant] on the balloon, ${ }^{51}$ But it is hardly necessary to rehearse here the details of this journey, or to recount the emotionally charged narrative of which these details continue to be generative. ${ }^{52}$ What is important here is how the balloon journey can be understood as a processual transformation in altitude, temperature, direction and 
precipitation: and how such transformations in an affective-atmospheric field are registered as a series of sensed modifications of a body's capacity to affect and be affected.

\section{Engineering expectancy}

Even as The Eagle disappears to the world, something of the Andrée expedition remains: a distributed space of expectancy existing as a diffuse field of potential from which precipitates rumours, spectral sightings, and ghostly balloons. Andrée's expedition is not of course the first balloon flight generative of such an affective atmosphere. The publics that gathered around early aerostatic bodies were animated by the expectation of ascension, and the ascent of a balloon could become an affective vector of hope, fear, wonder, terror, or amusement. As one commentator of the scene of such an early ascent put it: "two hundred thousand men [sic]. Lifting their hands in wonder, admiring, glad, astonished; some in tears for fear the intrepid physicists should come to harm, some on their knees overcome with emotion, but all following the aeronauts in spirit. ${ }^{53}$ Clearly, the launch of the Andrée expedition was only witnessed directly by a handful of people. Yet it was no less part of an affective atmosphere, albeit one far more distributed, and one amplified by appeals to both the universal imperatives of exploration and Swedish national aspirations. Thus, shortly after news of the launch of the expedition, an editorial in the Swedish newspaper Aftonbladet, described the members of the expedition as:

Three men alone meeting infinity and the unknown, sailing towards a goal which nobody in the world so far has reached. And below them a little crowd, standing helpless with its dread and with only some poor good wishes in its heart. A little crowd! But no, this handful of friends represents a whole nation, yes even more, the whole civilized world, whose eyes at the hour of departure and farewell follow the three explorers towards the far-away unknown ... and with these hopes we send the wish that today is expressed everywhere in Sweden and in Swedish homes: Good luck on your voyage. ${ }^{54}$

But the intensity of the field of expectancy in which the expedition is implicated is not just a matter of its resonance with certain pre-scripted emotional narratives. The very movement of The Eagle also potentializes the affectivity of this space: a virtual field from which the expedition (real or imagined) may actualize at various points. This process has been associated with balloon flight from its early days. Indeed, such was the affective power of early balloon flights that in September 1783 the French Government issued a pamphlet advising the populace of their possible appearance:

\footnotetext{
Anyone who shall see in the sky such a globe (which resembles 'la lune obscurie) should be aware that, far from being an alarming phenomenon, it is only a machine, made of taffetas, or light canvas covered with paper, that cannot possibly cause any harm, and which will some day prove serviceable to the wants of society. ${ }^{55}$
}

Such pamphlets may have assuaged certain fears: but they heightened anticipation and expectation. Similarly, the distributed field of expectancy through which the expedition continued to persist even after its disappearance was engineered at least in part by the expedition itself. Andrée is reported to have claimed that no news of the expedition should be expected 'before three months; one year, perhaps two years, may elapse before you hear from us, and you may 
one day be surprised by news of our arrival somewhere. ${ }^{56}$ Before departing, and in anticipation of possible landings in Alaska, Canada, Greenland, the expedition had also arranged for leaflets to be distributed around the Arctic in an effort to send the information of [the] proposed journey to the places farthest north in touch with civilization'. ${ }^{57}$ These leaflets advised readers not to be worried if they should see a large spherical object floating through the sky: nor to be afraid of its occupants. Perhaps unsurprisingly, the distribution of such leaflets contributed to the generation and circulation of rumours about the sighting and discovery of Andrée's balloon. On 31 July 1897, 'an object was seen in the White Sea by the captain of a vessel passing through there which it was thought, might possibly be the Andrée balloon' ${ }^{58}$ Other sightings were made near the North Cape in Norway, Greenland, Russia, Canada, and bizarrely, in Germania, Iowa. ${ }^{59}$ Leaflets distributed in the Siberian Arctic seem to have proved particularly generative of sightings and rumours. On 11 February 1899, 18 months after the launch of the expedition, The New York Sun reported the apparent discovery, 'between Komo and the Pit River, in the Government of Yeniseisk, [of] a kind of cabin made of cloth and cordage, apparently belonging to a balloon. Nearby were found the bodies of three men, the head of one being crushed in. A number of instruments were scattered round'. ${ }^{60}$ This rumour prompted one of many rescue missions, none of which produced any concrete evidence of the fate of the expedition. It did however confirm the widespread existence of stories about the expedition, and of claims to know the whereabouts of its final resting place.

So from beyond the clouds, the expedition continued to resonate through the ongoing refrain of a question: Where is Andrée? Hints of possible answers to this question were revealed through the circulation of various bodies - animate and inanimate - whose differential speed of movement seemed to attest to the potential fate of the expedition. The expedition carried with it 36 carrier pigeons, sponsored by the Swedish newspaper Aftonbladet, to be used as a means of communication. On 15 July 1897 (four days after the departure of the expedition), at $80^{\circ} 44^{\prime}$, $\mathrm{N} 20^{\circ} 20^{\prime} \mathrm{E}$, the crew of a Norwegian sealer, The Alken, notices a strange bird settling on the deck. The skipper shoots the bird, at which point it falls overboard. Some hours later The Alken meets another ship, the crew of which suggest that the bird might have been one of Andrée's carrier pigeons. Returning to the location, the crew of The Alken manage to find the dead bird floating in the water, on which they find a small cylinder:

From Andrée's Polar Expedition to Aftonbladet, Stockholm. Open the cylinder from the side and take out two letters; of these the one in ordinary hand is to be wired to Aftonbladet, the one in shorthand is to be sent by the first post to the paper.

Despite these instructions, the cylinder actually contains only one letter:

13th July

12.30 Midday, lat. $82^{\circ} 2^{\prime}$ long. $15^{\circ} 5^{\prime}$ E. good speed to E. $10^{\circ}$ south. All well on board. This is the third pigeon post. ${ }^{61}$

Other pigeons bearing news from Andrée are reportedly found at Soevda, in Rifylke, and near Tromsø Island, in Norway, the first of which contained the message: North Pole passed, fifteenth'. On the second, the message was reportedly: 'North Pole, 142 W., 47 minutes, 62 degrees'. ${ }^{62}$ A 'plague of pigeons', real and imagined, begins appearing across Sweden, Norway 
and Northern Europe, and 'the impression is conveyed at certain times that the woods are full of pigeons', all of which seem to 'bear on various parts of their persons numbers of words of highly cryptogramic [sic] character'. ${ }^{63}$

As time passes the intensity of this space of expectancy fades, amplified by the timelagged appearance of circulating materials from the expedition. The expedition carried with it a number of buoys, 'which we intend to drop upon the ice at intervals. These, drifting with the ice in the ocean currents, may take to those farther south information of the experiences and hopes of the three of us who propose to stake our lives upon the success of this aerial trial with chance'. ${ }^{64}$ At Kollafjord, on the North East Coast of Iceland, on 14 May 1899 (672 days after the departure of the expedition) a small buoy (No. 7) is found on a beach, sent to Reykjavik, before arriving in Stockholm via Copenhagen:

This buoy has been thrown from Andrée's balloon at 10h. 55min. GMT on the 11 th of July 1897 in about $82^{\circ}$ latitude and $25^{\circ}$ long. E. fr. Gr. We are floating at a height of 600 metres.

All well.

Andrée Strindberg Fraenkel. ${ }^{65}$

On 11 September 1899, at King Charles Land, in the South Eastern part of the Svalbard Archipelago, the expedition's Polar Buoy is found. This was to be dropped when the expedition had reached the pole. No message is contained within. On 27 August 1900 (1142 days after the departure of the expedition) another buoy is found in Lögsletten, Finnmark, Norway:

Buoy No. 4. The first thrown out on the 11 th July, 10 p.m. G.M.T.

Our journey has hitherto gone well. We are still moving on at height of $250 \mathrm{~m}$. (830ft) in a direction which at first was N. $10^{\circ}$ E. declination, but later N. $45^{\circ}$ E declination. Four carrier-pigeons were sent off at $5 \mathrm{~h} 40$ p.m. Greenw. time. They flew westerly. We are now in over the ice, which is much broken up in all directions. Weather magnificent. In best of humours.

Andrée Strindberg Fraenkel

Above the clouds since 7.45 G.M.T. ${ }^{66}$

So, long after the disappearance of Andree and his companions, the expedition continues to circulate as a field of movement, a barely sensed field of affects. As Deleuze writes, such affects are 'not individuated like people and things, but nevertheless they do not blend into the indifference of the world. They have singularities which enter into virtual conjunction and each time constitute a complex entity. It is like points of melting, of boiling, of condensation, of coagulation'. ${ }^{67}$ This remotely sensed field of affect is individuated once again when, on 6 August 1930, a Norwegian ship, The Braatvag, taking advantage of unusually mild weather, makes a brief stop at the remote, ice-covered, and often ice-bound White Island (Kvitøya), 100 miles northeast of Svalbard, where some of the crew go ashore to hunt and flense walruses. While ashore, the crew find a canvas boat half buried in the snow. Subsequent digging reveals the remains of the 1897 Andrée expedition: the bodies of two of the expedition members, believed to be Andrée and Strindberg; diaries and notebooks; and various artefacts. 
Soon afterwards, a second ship - The Isbjörn - visits the site and recovers further material, including a third body, and some photographic film. The discovery of the remains becomes an international news sensation. The diffuse field in which the expedition had been latent is actualized, precipitating as a narrative serialized in newspapers accompanied by retouched versions of the surviving photographic exposures. And the remains are hewn and picked from the ground, and returned, in pieces, to Stockholm, where they become the moving material for a period of national mourning at the centre of which is a nostalgic longing for the heroic enactment of national aspiration. ${ }^{68}$

\section{Conclusion}

Rather than revisiting the Andrée expedition in order to trace the wider cultural geographies in which its undertaking or rediscovery is implicated, this article has provided an account of the expedition that takes seriously how its materialities come to consist through different configurations of moving bodies: through the movement of The Eagle rising and falling, affecting and being affected by changes in a field of atmospheric affects; through this movement registering as feeling in moving, sensing bodies; and through a distributed atmospheric field of circulating materials moving at differential rates from which obviously emotional geographies precipitate - narratives of hope, longing, sadness, despair, and joy through which the afterlife of the expedition continues to persist.

In mapping the moving geographies of the Andrée expedition thus, the article has sought to exemplify how atmospheric space can be conceived in terms of a processual materiality that runs transversal to the meteorological and the affective. Atmosphere conceived thus is not only an imagined space. Nor is it only a space rendered explicit or constructed via various scientific practices. It is also a space of affective materiality actualized through the ongoing movement of bodies where bodies, following Spinoza, are defined not so much in terms of their phenomenological integrity or humanness but in terms of their capacity to affect and be affected. Situated along this Spinozist cartography, the affectivity of moving bodies does indeed become more abstract, less immediately fleshy, and less tangibly human. Bodies become aerostats, gusts of wind, enveloped hydrogen, circulating materials. And, as such, Spinoza's writing supports an affective geography open to how pipes and cables, guide-ropes and drag-lines, and assorted technical devices participate in the engineering of distinctive kinds of affective materials. ${ }^{69}$ Andrée, after all, was an engineer. And the balloon expedition was an attempt to engineer a technical solution to the problem of polar travel by addressing atmosphere as a field of affect.

Yet, while it forces a recognition that the affectivity of atmosphere is not reducible to emotional experience, foregrounding Spinoza as part of an attempt to understand atmosphere as a field of affect does not preclude attending to how this field registers in the 'relational-matrices' of particular kinds of sensing bodies. ${ }^{70}$ Thus, and second, the article has sought to demonstrate how the affective atmospheres through which aerostatic bodies move are best conceived in ways that acknowledge the passage from and between affect (as a pre-personal field of intensity), feeling (as that intensity registered in a sensing body), and emotion (as that felt intensity expressed in a socio-culturally recognizable form). So, while it can be conceived of as an attempt to engineer a way of addressing atmosphere in technical and abstract terms, 
the Andrée expedition also involved the sensing of an abstract field through the feeling of movement and disorientation. Furthermore, the expedition was also generative of a distributed field of affectivity, which, although barely and remotely sensed, can precipitate through the appearance of various materials, texts, and images. In this way, it becomes possible to think of the Andrée expedition as a passage through atmospheric spaces of affective movement that do not obey the neat ontological distinctions that, as Tim Ingold suggests, have so often framed engagements with earth-atmosphere relations. ${ }^{71}$

Rethinking the affectivity of atmospheric spaces and aerostatic bodies in this way is not only of consequence for attempts to think of the cultural geographies of which such a 'strange journey' as the Jules Verne-like Andrée expedition is generative. ${ }^{72}$ It might also become part of the development of conceptual vocabularies with which to rethink the logics of materiality that inform research within and beyond human geography. As Ben Anderson and John Wylie argue in an important forthcoming paper, such vocabularies are crucial to any effort to rethink the materialities of which geographies consist. ${ }^{73}$ While it is by no means the only conceptual vehicle through which such thinking might be cultivated, atmosphere is particularly resonant, moving as it does between the materiality of meteorology and affectivity, and in ways that invoke a space simultaneously distributed and virtual but from which certain intensities are registered actually - as felt variations of pressure, density, or buoyancy. The ongoing development of such vocabularies is perhaps of particular importance in a world where atmosphere and airspace are both becoming rendered increasingly explicit as political and techno-scientific zones, while also remaining spaces whose affects are registered, even if often only remotely, through the modification, however minor, of sensing, moving bodies. ${ }^{74}$ Addressing the different techniques and technologies through which such sensing takes place, should be a central aspect of any future attempt to rethink air and atmosphere, regardless of the altitude, speed, or affective intensity of the vehicle through which this sensing is enacted.

\section{Acknowledgements}

Thanks to Phil Crang, Mona Domosh, and Tim Cresswell, and to three anonymous referees for their comments on the initial version of this article. Some of the material here was presented at the Department of Geography, University of Bergen and at the RGS-IBG annual meeting in 2006. Thanks also to Mike Pearson for supportive comments about an earlier version, and to John Wylie and Nigel Thrift. I am particularly indebted to Håkan Jorikson and the staff at both the Grenna Museum and to Bob Headland and the staff at the Scott Polar Research Institute. This paper is based upon research supported by a British Academy Small Grant.

\section{Biographical note}

Derek P. McCormack is University Lecturer in Geography at the School of Geography, University of Oxford, and a fellow of Hertford College, Oxford. He has published on geographies of affectivity and materials, the spaces of moving bodies, and on the relation between cinema and geopolitics. He can be contacted at: School of Geography, Oxford University Centre for the Environment, South Parks Road, Oxford OX1, UK; email: derek.mccormack@ouce.ox.ac.uk 


\section{Notes}

1 Teresa Brennan, The transmission of affect (Cornell, Ithaca, 2004).

2 See Sarah Whatmore, 'Materialist returns: practising cultural geography in and for a more than human world', Cultural geographies 13(2006), pp. 600-9; see also Ben Anderson and John Wylie, 'On geography and materiality', Environment and planning A 41(1) (forthcoming).

3 See, for instance, John Wylie, 'A single day's walking: narrating self and landscape on the southwest coast path', Transactions of the Institute of British Geographers 30 (2005), pp. 234-47; Hayden Lorimer, 'Herding memories of humans and animals', Environment and planning D: society and space 24 (2006), pp. 497-518; John Wylie and Mitch Rose, 'Animating landscape', Environment and planning D: society and space 24 (2006), pp. 475-9.

4 See Kay Anderson and Susan Smith 'Emotional geographies', Transactions of the Institute of British Geographers 26 (2001), pp. 7-10; Brian Massumi, Parables for the virtual: movement, affect, sensation (Durham, NC, Duke University Press, 2002); Derek P. McCormack, 'An event of geographical ethics in spaces of affect', Transactions of the Institute of British Geographers 28 (2003), pp. 488-507; Nigel Thrift, 'Intensities of feeling: towards a spatial politics of affect', Geografiska annaler 86B (2004), pp. 57-78. Eric Shouse, 'Feeling, emotion, affect', $M / C$ journal 8 (2005). Available online at: http://journal.media-culture.org.au/0512/03-shouse.php [accessed 02/06/07]; Ben Anderson, 'Becoming and being hopeful: towards a theory of affect', Environment and planning D: society and space 24 (2006), pp. 733-52.

5 See Derek P. McCornack, 'Aerostatic spacing: on things becoming lighter than air', Transactions of the Institute of British Geographers (forthcoming), and Jane Bennett, 'The force of things: Steps to an ecology of matter', Political theory 32 (2004), pp. 347-72.

6 Tim Ingold, 'Rethinking the animate, re-animating thought', Ethnos 71 (2006), pp. 9-20; 'The eye of the storm: visual perception and the weather', Visual studies 20 (2005), pp. 98-104.

7 Ingold, 'Rethinking the animate', p. 17.

8 Katherine Anderson, 'Looking at the sky: the visual context of Victorian meteorology', British journal for the history of science 36 (2003), pp. 301-32; Lucian Boia, The weather in the imagination (London, Reaktion, 2005). However, see also Simon Naylor, 'Nationalizing provincial weather: meteorology in nineteenth-century Cornwall', British journal for the history of science 39 (2006), pp. 407-33.

9 Ingold, 'Rethinking the animate', p. 17.

10 For a discussion of the affectivity of scientific practice, see Jamie Lorimer, 'Counting corncrakes: the affective science of corncrake surveillance', Social studies of science (forthcoming, 2008).

11 As such, a discussion of balloons as aerostatic bodies might also be situated in relation to an emerging concern with airspace, aeromobility, and outer-space within human geography. A discussion of this forms the basis of another forthcoming paper by the author, McCormack (forthcoming), but see; Peter Adey, Lucy Budd and Phil Hubbard 'Flying lessons: exploring the social and, cultural geographies of global air travel', Progress in human geography 31 (2007), pp. 773-91; Fraser MacDonald, 'Anti-astropolitik: outer space and the orbit of geography', Progress in human geography 31 (2007), pp. 592-615.

12 Peter Sloterdijk, Écumes: sphères III (Hachette, Paris, 2005).

13 Jules Verne, Around the world in eighty days and five weeks in a balloon (Ware, Herts, Wordsworth Classics, 2002). See also Michel Serres, 'Jules Verne’s strange journeys', Yale French studies 52 (1975), pp. 174-88.

14 Cited in Elaine Freedgood, Victorian writing on risk: imagining a safe England, (Cambridge, University of Cambridge Press, 2000), pp. 78.

15 Freedgood, Victorian writing.

16 Swedish Society for Anthropology and Geography, The Andrée diaries: being the diaries and records of S. A. Andrée, Nils Strindberg, and Knut Fraenkel, written during their balloon expedition to the North Pole in 1897 and discovered on White Island in 1930, together with a complete record of the expedition and discovery. 
Translated by E. Adams-Ray (London, Bodley Head, 1931), p. 34. While Andrée was by no means the first person to suggest such a venture, no previous plan had generated the support or financial backing required for its realization in practice. See Günther Sollinger, Andrée: the beginning of polar aviation 1895-1897 (Moscow, Russian Academy of Sciences, 2005).

17 See Lisa Bloom, Gender on ice: American ideologies of polar experience (Minneapolis, University of Minnesota Press, 1993); Francis Spufford, I may be some time: ice and the English imagination (London, Faber and Faber, 1996).

18 Such aspirations were intensified by the success of Norwegian Arctic exploration, embodied in the figure of Fritjof Nansen. In 1896, during Andrée's first, unsuccessful attempt to launch The Eagle, Nansen's ship Fram arrived at Danes Island, having been released from the ice into which it had been deliberately frozen for the past two and half years. Nansen was not on board: unbeknownst to his crew, he and a colleague were returning over the ice after an unsuccessful dash for the pole.

19 See Bloom, Gender on ice; John Wylie, 'Becoming-icy: Scott and Amundsen's South Polar Voyages, 1920-1913', Cultural geographies 9 (2002), pp. 249-65

20 Urban Wråkberg, 'Andrée's folly: time for reappraisal?', in Urban Wråkberg, ed., The centennial of S.A. Andrée's North Pole expedition (Royal Swedish Academy of Sciences, Stockholm, 1999) p. 60.

21 The Andrée diaries, p. 38.

22 Ibid., pp. 9-10.

23 Bendedict Spinoza, The ethics (Everyman, London, 1989), p. 49.

24 Ibid., p. 51.

25 William James, Essays in radical empiricism (Lincoln, NE, University of Nebraska Press, 1996), p. 71.

26 Peter Hallward, Out of this world: Deleuze and the philosophy of creation (London, Verso, 2006), p. 38.

27 The Andrée diaries, p. 48.

28 Ibid., p. 48.

29 Andrée's interest in wind has something to do with his reading, on a steamer to New York in 1876, of a popular account of weather and wind by a Swedish meteorologist. It also has something to do with his encountering, when attending the World Exhibition in Philadelphia as part of the same trip, the famous American balloonist John Wise (1808-97), whose plans for crossing the Atlantic by balloon had been widely publicized. Despite the interest shown by Andrée, Wise did not actually take him for a flight: it is not until 1892, in Stockholm, that Andrée made his first free balloon flight.

30 The Andrée diaries, p. 22.

31 Unlike today, there seems to have been little in the way of accurate observational data available to Andree about the nature of the atmospheric conditions that might be encountered by the expedition as it moves over the ice. The nature of the data available, and the question of how Andrée should have used this, both remain contested. See Sollinger, Andrée, and Wråkberg, 'Andrée's folly'. Wylie, 'Becoming-icy'; See also Spufford, I may be some time; Mike Pearson, 'No joke in petticoats: British polar expeditions and their theatrical presentations', Drama review 48 (2004), pp. 44-59; Kathryn Yusoff, 'Antarctic exposures: archives of the feeling body', Cultural geographies 14 (2007), pp. 211-33.

The Andrée diaries, p. 422.

Ibid., p. 423.

Ibid., p. 352.

Ibid., p. 36.

Ibid., p. 348.

Ibid., p. 421.

Ibid., p. 109.

Ibid., p. 353.

Ibid., p. 352. 
43 Ibid., p. 420.

44 Ibid., p. 422.

45 Ibid., p. 423.

46 Ibid., p. 429.

47 Ibid., p. 353.

48 Ibid., p. 355.

49 Ibid., p. 429.

50 Ibid., p. 431.

51 Ibid., p. 33, original emphasis.

52 The style of such account would necessarily owe much to the exemplary efforts of both Francis Spufford and John Wylie to narrate the journeys of Scott and Amundsen. See Spufford, 'I may be some time'; Wylie, 'Becoming-icy'.

53 Mercier, cited in Mi-Gyung Kim 'Balloon mania: news in the air', Endeavour 28 (2004), pp. 149-55, p. 149.

54 Cited in Sollinger, The beginning of polar aviation, p. 494.

55 Tom Rolt, The balloonists: the history of the first aeronauts (Sutton Publishing, Stroud, 2006), p. 36.

56 The Washington Star, 30 October 1897. Available online at: http://ku-prism.org/polarscientist/ andreemystery/andreeindex.html.

57 Louisville Dispatch, KY, 19 September 1897 Available online at: http://ku-prism.org/polarscientist/ andreemystery/andreeindex.html.

58 The Baltimore News, 31 July 1897 Available online at: http://ku-prism.org/polarscientist/andreemystery/ andreeindex.html.

59 Sollinger, The beginning of polar aviation.

60 The New York Sun, 11 February 1899. Available online at: http://ku-prism.org/polarscientist/ andreemystery/andreeindex.html.

61 The Andrée diaries, p. 89.

62 The New York Times, 23 July 1897. Available online at: http://ku-prism.org/polarscientist/andreemystery/ andreeindex.html.

63 Lonisville Dispatch, KY, 19 September 1897. Available online at: http://ku-prism.org/polarscientist/ andreemystery/andreeindex.html.

64 Ibid.

65 The Andrée diaries, p. 78.

66 Ibid., p. 77.

67 Gilles Deleuze, Cinema 1: the movement-image, trans. Hugh Tomlinson and Barbara Habberjam (University of Minnesota Press, Minneapolis, 1986), p. 106.

68 Sverker Sörlin 'The burial of an era: the home-coming of Andree as a national event', in Urban Wråkberg, ed., The centennial of S.A. Andrée's North Pole expedition (Royal Swedish Academy of Sciences, Stockholm, 1999), pp. 100-11.

69 Derek McCormack, 'For the love of pipes and cables: a response to Deborah Thien', Area 38 (2006), pp. 330-2.

70 Erin Manning, Politics of touch: sense, movement, and sovereignty (University of Minnesota Press, Minneapolis, 2007).

71 Anderson, 'Being and becoming hopeful'; Whatmore, 'Materialist re-turns'.

72 Serres, 'Jules Verne's strange journeys'.

73 Anderson and Wylie, 'On geography and materiality'.

74 Adey et al., 'Flying lessons'; MacDonald, 'Anti-astropolitike'. 